\title{
Cost-savings and potential cost-savings through the distribution of generic antiretroviral drugs within the statutory health insurance market of Germany between January 2017 and June 2019
}

Matthäus Lottes ${ }^{1 *}$, Viviane Bremer ${ }^{2}$, Christof Prugger ${ }^{3}$, Christian Kollan $^{2}$ and Daniel Schmidt ${ }^{2}$

\begin{abstract}
Background: Recent patent losses for antiretroviral drugs (ARV) have led to the debate of cost-saving through the replacement of patented drugs with generic drugs. The split of recommended single-tablet regimens (STR) into their single substance partners is one of the considerations mentioned in said debate. Particularly, generic tenofovir disoproxil/emtricitabine (TDF/FTC) is expected to hold untapped cost-saving potential, which may curb increasing overall expenditures for combined antiretroviral therapy (CART) within the statutory health insurance (SHI) of Germany.
\end{abstract}

Methods: Data of ARV reimbursed by the SHI were used to describe the trends of defined daily doses (DDD) as well as the revenue within the German ARV market. They were also used to determine the cost-savings of moving to generic drugs. The time period observed was between January 2017 and June 2019. The potential cost-savings were determined with following assumption in mind: the maximum possible use of generic ARV, including 1) the split of STR and replacing all substance partners with generic ones, and 2) replacing patented tenofovir alafenamide/emtricitabine (TAF/FTC) with generic TDF/FTC.

Results: Throughout the observation period, the DDD of generic ARV increased nearly five-fold while their revenue increased more than four-fold. Total cost-saving showed a sharp increase over the same period, with generic TDF/FTC accounting for a share of around $70 \%$. The largest potential cost-saving could have been achieved through replacing patented TAF/FTC with generic TDF/FTC, peaking at nearly $10 \%$ of total revenue, but showing decreasing trends in general.

Conclusion: The progressive distribution of generic ARV ensured increasing cost-savings but consequently curbed the potential cost-savings. Unique price reductions of generic TDF/FTC have played a pivotal role for these effects. In any case, substituting with generic ARV should not fail to adhere to the treatment guidelines and continue to consider the medical requirements for the treatment.

Keywords: Generic antiretroviral therapy, German statutory health insurance, Tenofovir disoproxil/emtricitabine, Tenofovir alafenamide/emtricitabine, Cost-saving, Potential cost-saving

\footnotetext{
*Correspondence: LottesM@rki.de

${ }^{1}$ Department of Methodology and Research Infrastructure, Information and Research Data Management, Robert Koch Institute, Berlin, Germany

Full list of author information is available at the end of the article
}

(c) The Author(s) 2022. Open Access This article is licensed under a Creative Commons Attribution 4.0 International License, which permits use, sharing, adaptation, distribution and reproduction in any medium or format, as long as you give appropriate credit to the original author(s) and the source, provide a link to the Creative Commons licence, and indicate if changes were made. The images or other third party material in this article are included in the article's Creative Commons licence, unless indicated otherwise in a credit line to the material. If material is not included in the article's Creative Commons licence and your intended use is not permitted by statutory regulation or exceeds the permitted use, you will need to obtain permission directly from the copyright holder. To view a copy of this licence, visit http://creativecommons.org/licenses/by/4.0/. The Creative Commons Public Domain Dedication waiver (http://creativeco mmons.org/publicdomain/zero/1.0/) applies to the data made available in this article, unless otherwise stated in a credit line to the data. 


\section{Background}

Combined antiretroviral therapy (cART) has substantially reduced the morbidity and mortality of the growing number of people infected with human immunodeficiency virus (HIV) [1-3]. HIV treatment in Germany has been very successful, with $93 \%$ of treated persons virally suppressed [4]. Therefore, cART has been the standard of care since its introduction in the mid-1990s and became the highest direct cost of HIV treatment in Germany, accounting for more than $85 \%$ of costs [5-7]. While the total expenditures for all drugs within the statutory health insurance (SHI) of Germany amounted to approximately 39 billion $€$ in 2018 [8], the expenditures on antiretroviral drugs (ARV) for patients with HIV, representing less than $1 \%$ of the total health insured community of Germany, amounted to approximately 1.3 billion $€$ $(\approx 3 \%$ of total drug expenditures) $[9,10]$.

Important regulations have been introduced by the German legislation with the aim of curbing prices of patented drugs as well as the increasing expenditures on pharmaceuticals incurred by sickness funds. These include, firstly, the German Act of reinforcing SHI competition that was passed in 2007 in order to facilitate the use of generic drugs after the patent expiration of branded drugs which is usually 20 years after the filings of patent applications [11-14]. Secondly, the Act on the Reform of the Market for Medical Products, passed in 2011, which obligated manufacturers to demonstrate the additional therapeutic benefit of newly developed pharmaceuticals. This additional benefit is the basis for the price negotiations between the Federal Association of Statutory Health Insurance Funds and pharmaceutical manufacturers $[15,16]$. Furthermore, as per the Social Code Book, German sickness funds are permitted to negotiate discount agreements with drug manufacturers [17].

Regardless of economic interests, the distribution of ARV must adhere to current treatment guidelines that recommend a combination of three drug classes for the initiation of the HIV therapy, preferably as a single-tablet regimen (STR) [18]. Generic ARV started to gain popularity in Germany between 2011 and 2013, starting with zidovudine, and followed by lamivudine, nevirapine and efavirenz [19]. The initial proportion of generic ARV in 2014 was rather small with $3.1 \%$ of total ARV distribution. When assuming the maximum possible use of generic ARV, the total potential cost-saving would have been $8 \%$ [20]. However, according to current treatment guidelines, most of these substances are no longer recommended for the initiation of the antiretroviral therapy, causing their market share to decline $[5,18]$. In contrast, the launch of generic tenofovir disoproxil/emtricitabine
(TDF/FTC) in August 2017 brought about a transformative change to the market of generic prescriptions. This was driven by its approval for pre-exposure prophylaxis, leading to unique price reduction of more than 90\% [21], whereas price reductions for generic drugs within the German ARV market usually range between 10 and 40\% [22]. Subsequently, a high budget impact was expected, as more than $70 \%$ of the cART regimens in Germany were based on TDF/FTC in 2017 [23].

Since almost one-third of the available ARV lost their patent protections, the debate about cost-saving through generic replacements is still ongoing [5, 24-27]. This entails the split of newer and recommended STR into their single substance partners, irrespective of the medical indication for a change of treatment and accepting the possible consequences of higher pill burdens for patients [28-30].

In this study, our aim was to firstly describe the current ARV market within the German SHI. Secondly, we aimed to determine the cost-savings achieved through the distribution of generic drugs, focusing particularly on TDF/FTC. Our third aim was to determine the potential cost-savings that could be achieved additionally when assuming the maximum possible use of generic ARV. This includes the splitting of STR, replacing all substance partners with generic ones and replacing the patented drug tenofovir alafenamide/emtricitabine (TAF/FTC) with generic TDF/FTC.

\section{Methods}

\section{Data source}

Insight Health ${ }^{\mathrm{TM}}$ provided the data of distributed ARV for the years 2013 to the end of the second quarter of 2019. These data were collected from the billing centers and included all prescriptions reimbursed to pharmacies by the German SHI. The data account for more than $99 \%$ of distributed ARV covered by the SHI.

\section{Data structure and editing}

The dataset included all ARV by pharmaceutical registration numbers distributed on a monthly basis, regardless of whether the use was for prevention or treatment of HIV. Additional relevant items were product name, substance name, drug class, Anatomical Therapeutic Chemical (ATC) classification code which is unique for each ARV and thus will be used synonymously throughout the paper [31], patent status, pharmacy retail price and defined daily dose (DDD). DDD was determined as the daily per capita consumption for each antiretroviral substance grouped by ATC, based on manufacturer specifications and guidelines [18, 32]. The ATC codes considered are listed by substance 
Table 1 Anatomical Therapeutic Chemical (ATC) classifications by substance class, antiretroviral substances and quarter/year of launch as a generic drug in Germany (grey: available as generic drug)

\begin{tabular}{|c|c|c|c|}
\hline Substance dass & ATC & Antiretroviral substance & $\begin{array}{l}\text { Market launch as } \\
\text { generic drug }\end{array}$ \\
\hline \multirow{16}{*}{$\begin{array}{l}\text { Combination preparation } \\
\text { (Combi) }\end{array}$} & J05AR01 & Zdovudine/Lamivudine & $2 / 2013$ \\
\hline & J05AR02 & Abacavir/Lamivudine & 2/2016 \\
\hline & J05AR03 & Tenofovir disoproxil/Emtricitabine & $3 / 2017$ \\
\hline & J05AR04 & Zdovudine/Lamivudine/Abacavir & \\
\hline & J05AR06 & Tenofovir disoproxil/Emtricitabine/Efavirenz & $4 / 2017$ \\
\hline & J05AR08 & Tenofovir disoproxil/Emtricitabine/Rilpivirine & \\
\hline & J05AR09 & Tenofovir disoproxil/Emtricitabine/Elvitegravir/Cobicistat & \\
\hline & J05AR10 & Lopinavir/Ritonavir & \\
\hline & J05AR13 & Abacavir/Lamivudine/Dolutegravir & \\
\hline & J05AR17 & Tenofovir alafenamide/Emtricitabine & \\
\hline & J05AR18 & Tenofovir alafenamide/Emtricitabine/Elvitegravir/Cobicistat & \\
\hline & J05AR19 & Tenofovir alafenamide/Emtricitabine/Rilpivirine & \\
\hline & J05AR20 & Tenofovir alafenamide/Emtricitabine/Bictegravir & \\
\hline & J05AR21 & Dolutegravir/Rilpivirine & \\
\hline & J05AR22 & Tenofovir alafenamide/Emtricitabine/Darunavir/Cobicistat & \\
\hline & J05AR24 & Tenofovir disoproxil/Lamivudine/Doravirine & \\
\hline \multirow[t]{2}{*}{ Entry inhibitor (Entryl) } & J05AX07 & Enfuvirtid & \\
\hline & J05AX09 & Maraviroc & \\
\hline \multirow[t]{2}{*}{ Integrase inhibitor (II) } & J05AX08 & Raltegravir & \\
\hline & J05AX12 & Dolutegravir & \\
\hline \multirow{5}{*}{$\begin{array}{l}\text { Non-nudeoside reverse } \\
\text { transciptase inhibitor (NNRII) }\end{array}$} & J05AG01 & Nevirapine & $3 / 2013$ \\
\hline & J05AG03 & Efavirenz & $4 / 2013$ \\
\hline & J05AG04 & Etravirine & \\
\hline & J05AG05 & Rilpivirine & \\
\hline & J05AG06 & Doravirine & \\
\hline \multirow{6}{*}{$\begin{array}{l}\text { Nudeoside reverse } \\
\text { transojptase inhibitor (NRII) }\end{array}$} & J05AF01 & Zdovudine & $1 / 2011$ \\
\hline & J05AF02 & Diadanosine & \\
\hline & J05AF04 & Stavudine & \\
\hline & J05AF05 & Lamivudine & $1 / 2013$ \\
\hline & J05AF06 & Abacavir & $4 / 2016$ \\
\hline & J05AF09 & Emtricitabine & \\
\hline \multirow[t]{6}{*}{ Protease inhibitor (PI) } & J05AE01 & Saqinavir & \\
\hline & J05AE02 & Indinavir & \\
\hline & J05AE07 & Fosamprenavir & \\
\hline & J05AE08 & Atazanvir & 2/2019 \\
\hline & J05AE09 & Tipranavir & \\
\hline & J05AE10 & Darunavir & $1 / 2019$ \\
\hline \multirow[t]{2}{*}{ Booster } & J05AE03 & Ritonavir & $3 / 2018$ \\
\hline & V03AX03 & Cobicistat & \\
\hline
\end{tabular}

class, antiretroviral substances and quarter/year of launch as a generic drug (Table 1). For the sake of clarity, two items were excluded from the analysis: 1) ARV that were not available in tablet form and 2) the DDD of single TDF mainly used for the treatment of hepatitis B [33-35]. The DDD of the booster substances ritonavir and cobicistat were quantified by counting the DDD of the necessary combined protease inhibitor, ATC class J05AE (Table 1), and their recommended boosting doses $[18,36]$.
Determination of cost-savings and potential cost-savings The observational period was limited from January 2017 to June 2019 in order to account for market launches of generic alternatives. For all ARV, the DDD and corresponding revenues were determined in accordance with their respective patent status: patented, patent expired or generic. Additionally, the DDD and revenues were determined for a few ARV with an expired patent that do not have an equivalent generic substitute. 


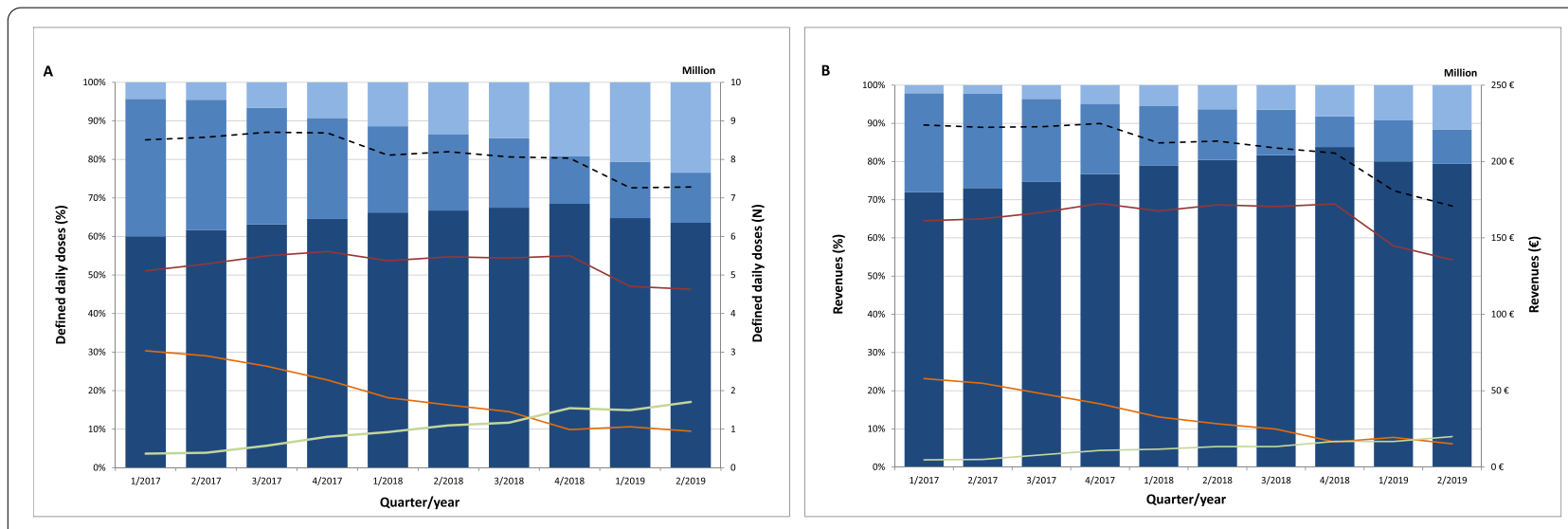

- Exprice patent - Generic

Fig. 1 Defined daily doses (N, \%) and revenues (million $€$, \%) of antiretroviral drugs by patent status between 1/2017 and 2/2019

To quantify cost-savings and potential cost-savings, the pharmacy retail price for each ARV was first calculated as a weighted average of patent status (Supplementary Table S1). Secondly, the exclusive distribution of patented or expired patent ARV has been assumed in order to determine cost-savings of moving to generic drugs. Thirdly, the maximum possible use of generic ARV has been assumed as explained before in order to determine the potential cost-savings. This includes the splitting of STR, replacing all substance partners with generic ones and replacing patented TAF/FTC with generic TDF/FTC.

\section{Results}

From $1 / 2017$ to $2 / 2019$, the DDD of generic ARV increased nearly five-fold and their revenue by more than four-fold (Fig. $1 \mathrm{~A}$ and B). The DDD of ARV with an expired patent, on the other hand, decreased continuously, while patented ARV showed a sharp decrease for the first time in 2019. In total, DDD and revenue decreased stepwise by one-sixth and by almost onefourth, respectively.

The total cost-saving through the distribution of generic ARV showed a steep increase from 1.2 million $€$ (< $1 \%$ of total revenues) in $1 / 2017$ to 17.3 million $€(10 \%$ of total revenues) in $2 / 2019$ (Fig. 2). TDF/FTC leveled off at about $70 \%$ from $4 / 2017$ until 4/2018, and the decline in its cost-savings thereafter may be attributed to the launch of generic darunavir (DRV) in 1/2019 (Table 1). A detailed overview of the cost-savings achieved by each generic ARV can be found in Supplementary Table S2.

Generic TDF/FTC also has a pivotal influence on the course of potential cost-savings, particular for the splitting and generic replacement of tenofovir disoproxil/ emtricitabine/rilpivirine and tenofovir disoproxil/ emtricitabine/efavirenz (Fig. 3) as well as for TAF/ FTC and tenofovir alafenamide/emtricitabine/rilpivirine (Fig. 4). However, maximizing generic substitution would not have led consistently into potential cost-savings and overall downward trends have been observed since mid-2018. A detailed overview of the potential cost-savings of each ARV can be found in Supplementary Tables S3, S4, S5. Accordingly, the combination of potential cost-savings through a maximum possible use of generic ARV increased to 38.3 million $€$ in $2 / 2018$ (18\% of total revenues) and then decreased to 19.2 million $€$ in $2 / 2019$ (11\% of total revenues).

\section{Discussion}

Using data of ARV reimbursed by the SHI, this study shows the increasing influence of generic ARV in Germany, accounting for almost one-fourth of the total ARV market in mid-2019. In particular, the unique price reductions for generic TDF/FTC substantially affected the course of cost-savings and potential cost-savings between January 2017 and June 2019. Assuming the maximum possible use of generic ARV, the splitting of STR and replacing TAF/FTC with generic TDF/FTC specifically, revealed substantial potential cost-savings.

\section{Market situation of antiretroviral drugs}

The results showed a remarkable increase of distributed generic DDD (Fig. 1) as a result of the efforts of German sickness funds aiming to compensate the increasing cART expenditures by distributing generic ARV [17, 24]. However, our data suggested insufficient generic substitution for ARV with an expired patent, such as 


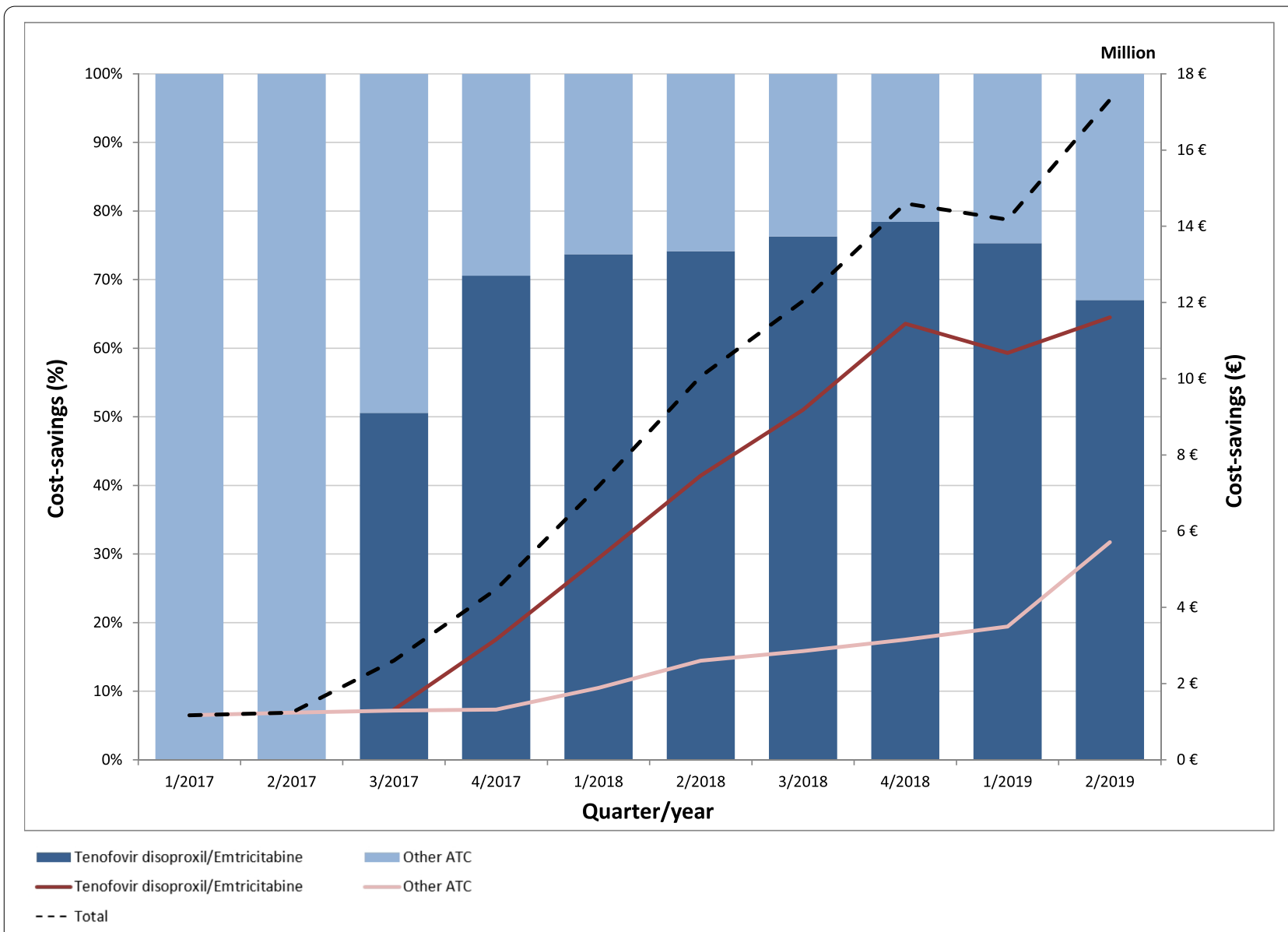

Fig. 2 Cost-savings (million $€, \%$ ) through the distribution of generic antiretroviral drugs between 1/2017 and 2/2019

zidovudine, lamivudine or abacavir (Supplementary Table S1).

Discount agreements between sickness funds and drug manufacturers are an important factor to consider as they are binding for the distributing pharmacies [14, 37, 38]. However, as our calculations were solely based on the pharmacy retail price, we were not able to explicitly quantify the amounts of discount agreements. One may roughly approximate the discount agreements for ARV with an expired patent to be in the comparable range as the cheaper pharmacy retail price of their equivalent generic drugs.

Against the widespread use of generic ARV, the current guidelines recommend the treatment with patented STR [18], leading into their increased distribution (Supplementary Table S1) and, in turn, the observed decline of overall DDD (Fig. 1A).

\section{Cost-savings through the distribution of generic antiretrovirals}

This study emphasizes the significant influence of generic TDF/FTC for cost-saving within the German ARV market, accounting for a share of approximate $70 \%$ (Fig. 2), triggered by its immense price drop in combination with the approval for the pre-exposure prophylaxis $[21,23]$. The distribution of other generic ARV, on the other hand, accounted for a much smaller share of total cost-savings (Supplementary Table S1). This may certainly also have been due to their comparatively lower price reduction of between 10 and 40\% [22, 23]. Overall, the growing importance of distributing generic ARV was confirmed, considering the strong increase of the total cost-saving from less than $1 \%(\approx 1.2$ million $€)$ of total ARV evenue in early 2017, to about $10 \%(\approx 17.3$ million $€$ ) in mid-2019 (Supplementary Table S2). 


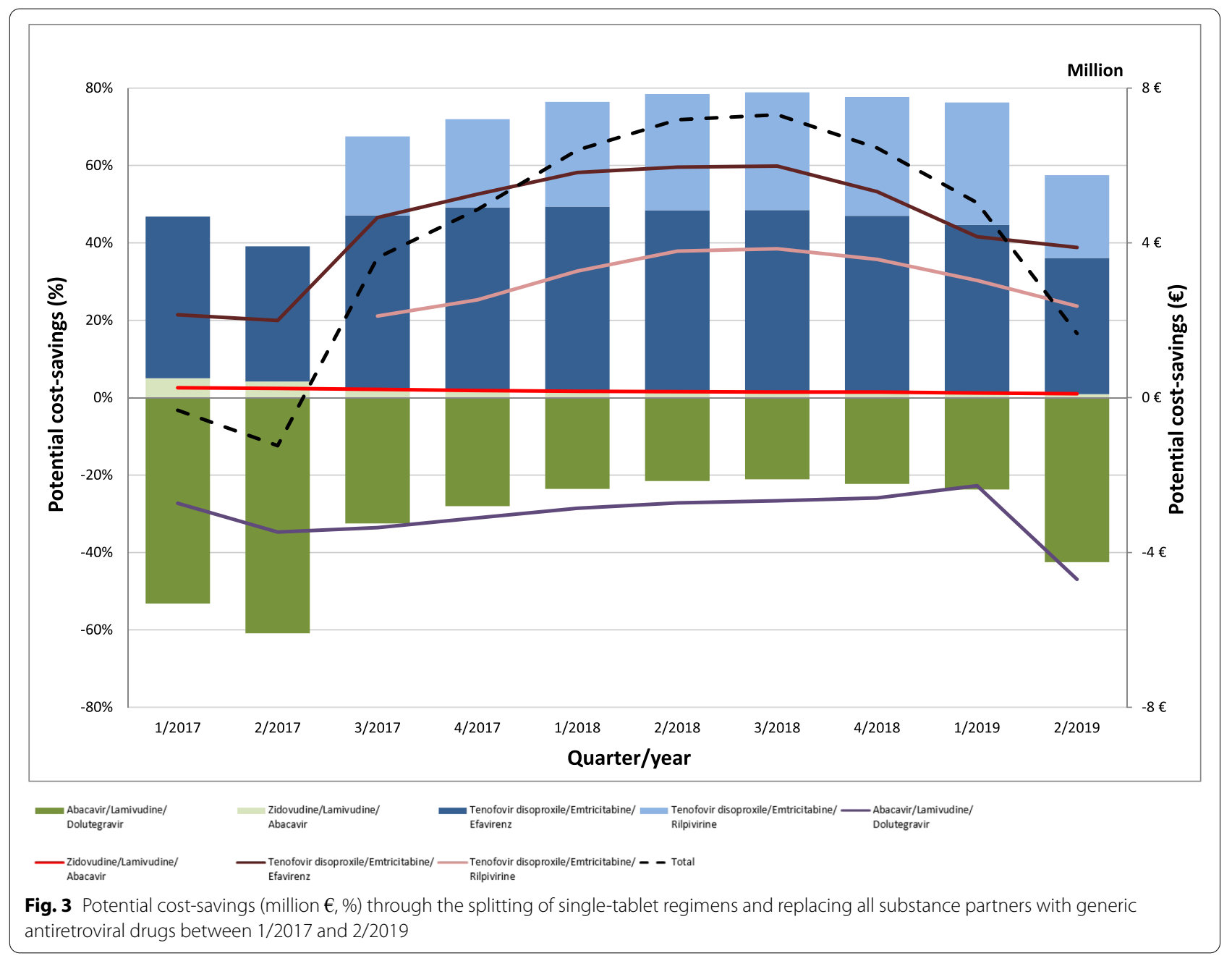

\section{Potential cost-savings through the maximum possible use of generic antiretrovirals}

Generic TDF/FTC also had a decisive role when assuming the maximum possible use of generic drugs in order to determine the potential cost-savings within the German ARV market. This mainly related to the split of STR (Fig. 3) and the replacement of patented TAF/FTC (Fig. 4). However, splitting STR into their single substance partners and replacing them with generic ARV did not guaranteed potential costsavings, as observed for tenofovir disoproxil/lamivudine/doravirine and abacavir/lamivudine/dolutegravir (Fig. 3).

Moreover, this approach goes against the general trend of antiretroviral therapy [39-42] and implies a higher pill burden for patients who are used to taking STR, which might lower their treatment adherence [29, 30]. One should further note, that patented TAF/FTC is still recommended as preferred option for the initiation of antiretroviral therapy [18], which has shown superior renal and bone safety compared to TDF/FTC [43-45]. Therefore, a change of treatment routine should not solely focus on the potential cost-savings but also on medical concerns, such as acute toxicities or treatment failures $[46,47]$.

Finally, this study shows the declining potential costsavings within the German ARV market, assuming the maximum possible use of generic drugs. Following this assumption, the total potential cost-savings would account for a rounded $11 \%(\approx 19.2$ million $€)$ of total ARV revenue in mid-2019 (Supplementary Table S3, S4, S5).

\section{Limitations}

This paper has several limitations. Firstly, the dataset used did not allow access to the private health insurance sector which accounted for approximately $11,5 \%$ of the total health insured community of Germany [10]. This may have given a more complete picture.

Secondly, our assumption to determine the potential cost-savings was not applicable for ARV containing 


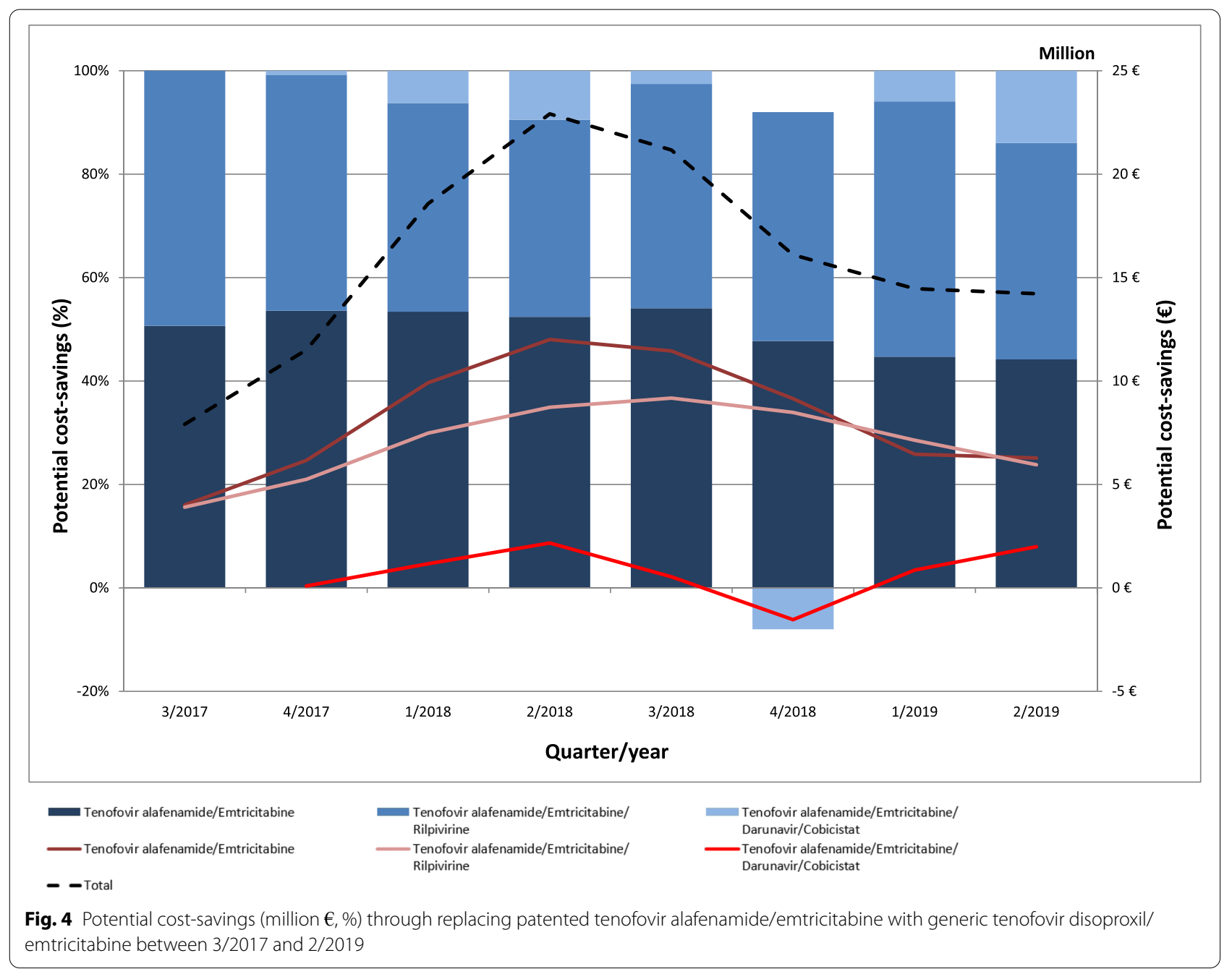

elvitegravir, bictegravir and lopinavir, since these substance partners are only available as a fixed combination preparation without generic substitute [18]. Since single TDF, assumed for the treatment of hepatitis B, was excluded, the split of tenofovir disoproxile/lamivudine/doravirine was also not considered (Table 1) [35].

Thirdly, we were informed that some pharmacies refused to transfer their data to the responsible billing centres in the health insurance regions of Berlin, North Rhine-Westphalia and Baden-Wuerttemberg at the end of 2018. This may have resulted in an additional decrease of total DDD, estimated at about $5-7 \%$, in 2019.

\section{Conclusion}

Generic drugs are progressively distributed in the German ARV market and ensure increasing cost-savings. Unique price reductions of generic TDF/FTC have played a pivotal role for both the cost-savings and potential cost-savings. However, as mentioned before, pursuing the maximum possible use of generic ARV should not fail to adhere to the treatment guidelines and consider the medical requirements for a change in treatment.

\section{Abbreviations \\ ARV: Antiretroviral drug; ATC: Anatomical Therapeutic Chemical classification; CART: Combined antiretroviral therapy; DDD: Defined daily dose; FTC: Emtric- itabine; HIV: Human immunodeficiency virus; SHI: Statutory health insur- ance; STR: Single-tablet regimen; TAF: Tenofovir alafenamide; TDF: Tenofovir disoproxil.}

\section{Supplementary Information}

The online version contains supplementary material available at https://doi. org/10.1186/s12913-021-07390-4.

Additional file 1. 


\section{Acknowledgements}

The authors would like to thank Insight Health ${ }^{\text {TM }}$ for providing the data of reimbursed antiretroviral drugs. Furthermore, we would like to thank especially our colleague Maria Helmrich for improving the language throughout the manuscript review.

\section{Authors' contributions}

$\mathrm{ML}$ contributed to the conception of the study and interpretation of the data, performed the data analysis and wrote the main manuscript. CK and DS were responsible for the study design, devised the estimation and interpretation of the data and helped to draft the manuscript. VB and CP supported the overall design and analysis approach and the writing of the manuscript. All authors participated in the critical discussion of the results, and all read and approved the final manuscript.

\section{Funding}

Open Access funding enabled and organized by Projekt DEAL.

\section{Availability of data and materials}

The dataset analyzed in this study is not publicly available, but can be made available upon reasonable request by Matthäus Lottes.

\section{Declarations}

\section{Ethics approval and consent to participate}

No administrative permissions were required to access the raw data. Insight Health $^{\mathrm{TM}}$ provides the antiretroviral therapy prescription data on a regular basis to the Unit for HIV/AIDS, STI and Blood-borne Infections at the Robert Koch Institute for research purpose.

\section{Consent for publication}

'Not applicable'.

\section{Competing interests}

$M L, V B, C P$ and DS declare that they have no competing interests. CK is small shareholder in ABBV and JNJ (CO) manufacturing the ATC codes J05AE03, J05AE10, J05AG04, J05AG05, J05AR10 and J05AR22.

\section{Author details}

${ }^{1}$ Department of Methodology and Research Infrastructure, Information and Research Data Management, Robert Koch Institute, Berlin, Germany. ${ }^{2}$ Department of Infectious Disease Epidemiology, HIV/AIDS, STI and Blood-borne Infections, Robert Koch Institute, Berlin, Germany. Institute of Public Health, Charité - Universitätsmedizin, Berlin, Germany.

Received: 22 July 2021 Accepted: 7 December 2021

Published online: 13 January 2022

\section{References}

1. Palella FJ, Delaney KM, Moorman AC, Loveless MO, Fuhrer J, Satten GA, et al. Declining morbidity and mortality among patients with advanced human immunodeficiency virus infection. N Engl J Med. 1998;338(13):853-60.

2. Murphy EL, Collier AC, Kalish LA, Assmann SF, Para MF, Flanigan TP, et al. Highly active antiretroviral therapy decreases mortality and morbidity in patients with advanced HIV disease. Ann Intern Med. 2001;135(1):17-26.

3. Walensky RP, Paltiel AD, Losina E, Mercincavage LM, Schackman BR, Sax $P E$, et al. The survival benefits of AIDS treatment in the United States. J Infect Dis. 2006;194(1):11-9.

4. Schmidt D, Kollan C, Stoll M, Hamouda O, Bremer V, Kurth T, et al. Everything counts - a method to determine viral suppression among people living with HIV using longitudinal data for the HIV care continuum results of two large, German, multi-center real-life cohort studies over 20 years (1999-2018). BMC Public Health. 2021;21(1):200.

5. Stoll M, Kollan C, Bergmann F, Bogner J, Faetkenheuer G, Fritzsche C, et al. Calculation of direct antiretroviral treatment costs and potential cost savings by using generics in the German HIV ClinSurv cohort. PLoS One. 2011;6(9):e23946.
6. Mostardt S, Hanhoff N, Wasem J, Goetzenich A, Schewe K, Wolf E, et al. Cost of HIV and determinants of health care costs in HIV-positive patients in Germany: results of the DAGNÄ K3A study. Eur J Health Econ. 2013;14(5):799-808.

7. Treskova M, Kuhlmann A, Bogner J, Hower M, Heiken H, Stellbrink H-J, et al. Analysis of contemporary HIV/AIDS health care costs in Germany: driving factors and distribution across antiretroviral therapy lines. Medicine. 2016;95(26):e3961

8. GKV-Spitzenverband. Ausgaben für einzelne Leistungsbereiche der GKV. Ausgaben für Arzneimittel (Apotheken, Versanthandel und Sonstige). 2018. https://www.gkv-spitzenverband.de/service/zahlen_und_grafiken/ gkv_kennzahlen/gkv_kennzahlen.jsp. Accessed 08 Nov 2021.

9. Gesundheitsberichterstattung des Bundes. Therapeutische Arzneimittel, die zu Lasten der gesetzlichen Krankenversicherung verordnet wurden. 2018. https://www.gbe-bund.de/gbe/!pkg_olap_tables.prc_set_page?p_ uid =gast\&p_aid $=24419356 \& p \_s p r a c h e=D \& p \_h e l p=2 \& p \_i n d n r=613 \& p \_$ ansnr=88826066\&p_version=5\&D.000=3740. Accessed 08 Nov 2021.

10. Bundesministerium für Gesundheit. Zahlen und Fakten zur Krankenversicherung. Kennzahlen, Daten, Bekanntmachungen. Informationen. 2021. https://www.bundesgesundheitsministerium.de/themen/krankenver sicherung/zahlen-und-fakten-zur-krankenversicherung/kennzahlendaten-bekanntmachungen.html. Accessed 08 Nov 2021.

11. Bundesanzeiger Verlag GmbH. Gesetz zur Stärkung des Wettbewerbs in der gesetzlichen Krankenversicherung (GKV-Wettbewerbsstärkungsgesetz-GKV-WSG). 2007. https://www.bgbl.de/xaver/bgbl/start.xav?start $\mathrm{bk}=$ Bundesanzeiger_BGBI\&start=//*\%255B@attr_id=\%2527bgbl10 7s0378.pdf\%2527\%255D\#_bgbl_\%2F\%2F*\%5B\%40attr_id\%3D\% 27bgbl107s0378.pdf\%27\%5D_1592064265408. Accessed 08 Nov 2021.

12. Fischer KE, Stargardt T. The diffusion of generics after patent expiry in Germany. Eur J Health Econ. 2016;17(8):1027-40.

13. UNITAID and the Medicines Patent Pool. Patents and licences on antiretrovirals: A Snapshot. 2015. https://medicinespatentpool.org/resourcepost/unitaid-mpp-report/. Accessed 08 Nov 2021.

14. Busse R, Blümel M, Knieps F, Bärnighausen T. Statutory health insurance in Germany: a health system shaped by 135 years of solidarity, self-governance, and competition. Lancet. 2017;390(10097):882-97.

15. Henschke C, Sundmacher L, Busse R. Structural changes in the German pharmaceutical market: Price setting mechanisms based on the early benefit evaluation. Health Policy. 2013;109(3):263-9.

16. Gemeinsamer Bundesausschuss. The benefit assessment of medicinal products in accordance with the German social code, book five (SGB V), section 35a. 2020. https://www.g-ba.de/english/benefitassessment/. Accessed 08 Nov 2021.

17. Bundesministerium der Justiz und für Verbraucherschutz. Sozialgesetzbuch (SGB) Fünftes Buch (V). Gesetzliche Krankenversicherung. § 130a Rabatte der pharmazeutischen Unternehmer. 2020. https://www.geset ze-im-internet.de/sgb_5/_130a.html. Accessed 08 Nov 2021.

18. Deutsche AIDS-Gesellschaft e.V. Deutsch-Österreichische Leitlinien zur antiretroviralen Therapie der HIV-Infektion. Version 8. 2019. https://daign et.de/site-content/hiv-leitlinien/hivleitlinien. Accessed 08 Nov 2021

19. Deutsche Aidshilfe. magazin.hiv. HIV-Generika - same same but different? 2013. https://magazin.hiv/2013/01/08/hiv-generika-same-same-but-diffe rent/. Accessed 08 Nov 2021.

20. Schmidt D, Kollan C, Stoll M, Stellenbrink HJ, Plettenberg A, Fätkenheuer $G$, et al. From Pills to Patients: Determination of the Number of People Living with HIV who Are Receiving Antiretroviral Therapy, Costs and Potential Cost-savings in Germany. 2015. https://www.abstractserver. com/eacsabstractarchive/. Accessed 04 Jan 2022.

21. European Medicines Agency. First medicine for HIV pre-exposure prophylaxis recommended for approval in the EU. 2016. https://www.ema. europa.eu/en/news/first-medicine-hiv-pre-exposure-prophylaxis-recom mended-approval-eu. Accessed 08 Nov 2021.

22. Stoll M. Generic antiretroviral drugs and their potential for cost reduction. MMW Fortschr Med. 2018;160(Suppl 2):37-9.

23. Stoll M, Balkin P, Goldbach J, Weber P, Peetroons B, Gokhale SB. Budget Impact Analysis Highlighting the Cost-Saving Potential of Generic Tenofovir Disoproxil Based Antiretroviral Therapy in Comparison with Tenofovir Alafenamide Based Treatment Regimens in the German Healthcare System. Journal of AIDS \& Clinical Research. 2017;09(01).

24. Hirnschall $\mathrm{G}$, de Joncheere $C$. Cost-effectiveness of generic antiretroviral therapy. Ann Intern Med. 2013;158(10):776. 
25. Ong KJ, van Hoek AJ, Harris RJ, Figueroa J, Waters L, Chau C, et al. HIV care cost in England: a cross-sectional analysis of antiretroviral treatment and the impact of generic introduction. HIV Med. 2019.

26. Kieran JA, O'Reilly E, O'Dea S, Bergin C, O'Leary A. Generic substitution of antiretrovirals: patients' and health care providers' opinions. Int J STD AIDS. 2017;28(12):1239-46.

27. Walensky RP, Sax PE, Nakamura YM, Weinstein MC, Pei PP, Freedberg $K A$, et al. Economic savings versus health losses: the cost-effectiveness of generic antiretroviral therapy in the United States. Ann Intern Med. 2013;158(2):84-92.

28. Van den Eynde E, Podzamczer D. Switch strategies in antiretroviral therapy regimens. Expert Rev Anti-Infect Ther. 2014;12(9):1055-74.

29. Sterrantino G, Santoro L, Bartolozzi D, Trotta M, Zaccarelli M. Self-reported adherence supports patient preference for the single tablet regimen (STR) in the current CART era. Patient preference and adherence. 2012:6:427-33.

30. Scott Sutton S, Magagnoli J, Hardin JW. Impact of pill burden on adherence, risk of hospitalization, and viral suppression in patients with HIV infection and AIDS receiving antiretroviral therapy. Pharmacotherapy. 2016:36(4):385-401.

31. European Medicines Agency. ATC code. 2021. https://www.ema.europa eu/en/glossary/atc-code. Accessed 08 Nov 2021

32. World Health Organization. Defined Daily Dose (DDD). Definition and general considerations. 2021. https://www.who.int/tools/atc-ddd-toolkit/ about-ddd. Accessed 08 Nov 2021.

33. Duggan JM, Akpanudo B, Shukla V, Gutterson G, Eitniear L, Sahloff EG. Alternative antiretroviral therapy formulations for patients unable to swallow solid oral dosage forms. American J Health-System Pharmacy. 2015;72(18):1555-65.

34. Marcellin P, Wong DK, Sievert W, Buggisch P, Petersen J, Flisiak R, et al. Ten-year efficacy and safety of tenofovir disoproxil fumarate treatment for chronic hepatitis B virus infection. Liver Int. 2019;39(10):1868-75.

35. Maisa A, Kollan C. An der Heiden M, van Bommel F, Cornberg M, Mauss $\mathrm{S}$, et al. increasing number of individuals receiving hepatitis $\mathrm{B}$ nucleos $(\mathrm{t})$ ide analogs therapy in Germany, 2008-2019. Front. Public Health. 2021;9:667253.

36. Marzolini C, Gibbons S, Khoo S, Back D. Cobicistat versus ritonavir boosting and differences in the drug-drug interaction profiles with co-medications. J Antimicrob Chemother. 2016;71(7):1755-8.

37. vfa-patientenportal. Rabattverträge und ihre Folgen. 2020. https://www. vfa-patientenportal.de/arzneimittel/verordnung-und-erstattung/rabat tvertraege-und-ihre-folgen.html. Accessed 08 Nov 2021.

38. GKV-Spitzenverand. Rahmenverträge zur Arzneimittelversorgung. Rahmenvertrag über die Arzneimittelversorgung nach § 129 Absatz 2 SGB V in der Fassung vom 01. April 2020. 2020. https://www.gkv-spitzenver band.de/media/dokumente/krankenversicherung_1/arzneimittel/rahme nvertraege/apotheken/Rahmenvertrag_nach_129_Abs.2_SGB_V_vom 01.04.2020_.pdf. Accessed 08 Nov 2021.

39. Costa JO, Ceccato M, Silveira MR, Bonolo PF, Reis EA, Acurcio FA. Effectiveness of antiretroviral therapy in the single-tablet regimen era. Rev Saude Publica. 2018;52:87.

40. Kapadia SN, Grant RR, German SB, Singh B, Davidow AL, Swaminathan S, et al. HIV virologic response better with single-tablet once daily regimens compared to multiple-tablet daily regimens. SAGE open medicine. 2018;6:2050312118816919.

41. Truong WR, Schafer JJ, Short WR. Once-daily, single-tablet regimens for the treatment of HIV-1 infection. P \& T : a peer-reviewed journal for formulary management. 2015;40(1):44-55.

42. Llibre JM, Clotet B. Once-daily single-tablet regimens: a long and winding road to excellence in antiretroviral treatment. AIDS Rev. 2012;14(3):168-78.

43. Wohl D, Oka S, Clumeck N, Clarke A, Brinson C, Stephens J, et al. Brief Report: A Randomized, Double-Blind Comparison of Tenofovir Alafenamide Versus Tenofovir Disoproxil Fumarate, Each Coformulated With Elvitegravir, Cobicistat, and Emtricitabine for Initial HIV-1 Treatment: Week 96 Results. J Acquired Immune Deficiency Syndromes (1999). 2016;72(1):58-64

44. Pozniak A, Arribas JR, Gathe J, Gupta SK, Post FA, Bloch M, et al. Switching to Tenofovir Alafenamide, Coformulated With Elvitegravir, Cobicistat, and Emtricitabine, in HIV-Infected Patients With Renal Impairment: 48-Week Results From a Single-Arm, Multicenter, Open-Label Phase
3 Study. Journal of acquired immune deficiency syndromes (1999). 2016;71(5):530-7.

45. Raffi F, Orkin C, Clarke A, Slama L, Gallant J, Daar E, et al. Brief report: long-term (96-week) efficacy and safety after switching from Tenofovir Disoproxil Fumarate to Tenofovir Alafenamide in HIV-infected, Virologically suppressed adults. JAIDS Journal of Acquired Immune Deficiency Syndromes. 2017;75(2):226-31.

46. Lake JE, Currier JS. Switching antiretroviral therapy to minimize metabolic complications. HIV Ther. 2010;4(6):693-711.

47. Eron JJ. Managing Antiretroviral Therapy: Changing Regimens, Resistance Testing, and the Risks from Structured Treatment Interruptions. J Infect Dis. 2008;197(Supplement_3):S261-S71.

\section{Publisher's Note}

Springer Nature remains neutral with regard to jurisdictional claims in published maps and institutional affiliations.
Ready to submit your research? Choose BMC and benefit from:

- fast, convenient online submission

- thorough peer review by experienced researchers in your field

- rapid publication on acceptance

- support for research data, including large and complex data types

- gold Open Access which fosters wider collaboration and increased citations

- maximum visibility for your research: over $100 \mathrm{M}$ website views per year

At BMC, research is always in progress.

Learn more biomedcentral.com/submissions 